\title{
LA PORNOGRAFÍA Y EL DOMINIO DE LO PORNOGRÁFICO EN EL ENSAYO ESPAÑOL [O QUÉ SUCEDE CON LA TENSIÓN ENTRE LAS NOCIONES DE SEXO Y PODER]
}

\author{
PORNOGRAPHY AND THE DOMAIN OF \\ PORNOGRAPHY IN THE SPANISH ESSAY \\ [OR WHAT HAPPENS TO THE RELATIONSHIP BETWEEN \\ THE NOTIONS OF SEX AND POWER] \\ Jara Calles Hidalgo \\ Stockholm Universitet \\ jara.calles@su.se
}

RESUMEN: El objetivo de este estudio es plantear un estado de la cuestión sobre el tratamiento que recibe un tema como el de la pornografía en el ensayo español contemporáneo, teniendo en cuenta que se trata de un tipo de discurso que cada vez tiene más que ver con las relaciones de poder que con el sexo (Braidotti). La pornificación gradual y ascendente de la sociedad, los nuevos formatos y las nuevas voces (en concreto, las femeninas) que han ido interviniendo en la configuración de una visión diferente, normalizada y más compleja de la pornografía, se acogen aquí como elementos de un interesante debate sobre las relaciones entre pornografía, sexualidad, identidad, género y poder.

PALABRAS CLAVE: ensayo español; feminismo; poder; pornografía; sexo

ABSTRACT: The objective of this study is to address the status of the issue regarding treatment given to a topic such as pornography in contemporary Spanish essays, taking into account that this is about a type of speech which has more often to do with the relationship of power than with sex (Braidotti). The gradual and increasing pornification of the society, the new formats and voices (in particular, the feminine ones) which have been influencing the configuration of a different vision, normalized and more complex about pornography, are included here as elements of an interesting debate about the relationship between pornography, sexuality, identity, gender and power.

Keywords: Spanish Essay; Feminism; Power; Pornography; Sex

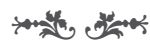




\section{EL CONTEXTO}

En torno al año 2010, en un artículo publicado en El País bajo el título "La filosofía en el vertedero", Félix de Azúa se lamentaba ante la situación moribunda de un género como el ensayístico, a excepción de una serie de autores a los que él hacía responsables de un "pensamiento filosófico" renovado y propio. Entre ellos, el autor mencionaba a José Luis Pardo, que en ese momento acababa de publicar el ensayo Nunca fue tan hermosa la basura (2010). Esto era algo que uno podía interpretar como un síntoma de retraso cultural, presente, de igual modo, en otro tipo de disciplinas artísticas, donde la auto-emulación había propiciado la puesta aparte de la "verdadera" investigación estética, entendida como ejercicio de innovación y compromiso con la actualidad.

Con el cambio de siglo, no obstante, esa necesidad de actualización de los patrones de pensamiento comenzó a hacerse más explícita y urgente y, por lo mismo, a ser relevada por pensadores que podrían considerarse "de nueva generación" (aunque no solamente). Puede pensarse, por ejemplo, en Eloy Fernández Porta, Paul B. Preciado (aka. Beatriz Preciado), Jorge Carrión, Vicente Luis Mora, Agustín Fernández Mallo, Jorge Fernández Gonzalo o Juan Freire; también al alimón con autores que se debatían entre ambas direcciones, pues estas no han de ser necesariamente opuestas a la hora de generar alternativas. Ese sería el caso de ciertos autores amparados por la institución cultural y la academia, pero cuya producción ensayística se caracteriza por haber acomodado sus discursos a las exigencias, tanto temáticas como estéticas, de este tiempo. Por ejemplo, autores como José Luis Molinuevo, Félix Duque o José Luis Brea, que optaron en su momento por afrontar la tesitura social inaugurada con el cambio de siglo ( $y$, especialmente, al cierre de su primera década), atendiendo a una realidad contemporánea, de forma transversal y compleja. La clave, posiblemente, estuvo en haber sabido conciliar la escritura académica con poéticas de naturaleza más excéntrica, propiciando de ese modo un equilibro entre el academicismo y una cultura más popular, que es lo que, tiempo después, ha ayudado a configurar la aparición de nuevos espacios para la crítica y la reflexión filosófica sobre el presente, de manera más efectiva y contemporánea.

Quizá por esto, siete años después, el titular ya no es el mismo. Así se ha planteado, de nuevo en El País, en un artículo elaborado por el periodista Carles Geli en el que se rechazaba la idea de crisis a favor del concepto de mutación con relación a la producción (y publicación) de ensayo en el territorio nacional. Un término, el de mutación, que encaja a la perfección en este contexto, teniendo en cuenta la tesitura actual del género, que en términos estéticos vive una suerte de renacimiento. Bajo el título "La gran mutación del ensayo", venía a ponerse de relieve la deriva del género hacia una alta divulgación de los contenidos, adaptados ahora a las exigencias de un público de cultura media, demandante de propuestas cada vez más dispersas y heterogéneas, pero sin renunciar por ello a la calidad y profundidad del pensamiento. Lo que habría cambiado, parece indicarse, es la metodología y, con ella, el propio discurso, que se vuelve transdisciplinar y pasa a adoptar un estilo de expresión más popular (entendiendo 
esto como un contrapunto al estilo más académico -o mejor, academicista- de la tradición ensayística nacional).

En palabras de Jordi Gracia, citado por Carles Geli en el artículo, este cambio de registro se debería especialmente a tres aspectos que tienen mucho que ver con la naturaleza del discurso: uno, el interés por parte de los autores por "ponerse al mismo nivel intelectual del lector"; dos, el hecho de abordar temas y fenómenos de actualidad y, tres, el hacerlo "estilísticamente mezclando documentación, ensayo y crónica" (Geli 2017).

Por supuesto, esto no significa que el ensayo se haya convertido en un género de masas pero, tal y como apunta Jesús Espino, subdirector de Akal y Siglo xxI, estos textos vienen a cubrir "el hueco de artículos largos que han desaparecido en prensa" (Geli 2017), respondiendo a las necesidades de un rango más amplio de lectores en busca de algo "más atractivo y disfrutable", con lo que "aprender y divertirse" (ahora en palabras de Miguel Aguilar, editor de Taurus y Debate, también citado en este artículo). Esto explica, por lo mismo, el éxito de catálogos como el de Errata naturae, con títulos dedicados a la ecología, el activismo y la conciencia social, las teleseries de última generación o las tendencias en novela gráfica actual, en tanto ejemplo de cómo la atención sobre los contenidos se ha desplazado en esta época hacia la manera de disfrutarlos. Una tendencia que resulta tangible en los modos de hacer ensayo hoy en día, abiertos a esa transversalidad e interdisciplinariedad de los contenidos que ocurre igualmente en otras esferas de la producción cultural.

Podría pensarse, entonces, que una escena como esta resulte favorable a la aparición de estudios teóricos sobre la pornografía, pero no tarda uno en darse cuenta de que trabajos de este tipo siguen siendo bien escasos, por mucho que el impacto comercial del porno sea indiscutible y la sociedad contemporánea se haya convertido en una "pornógrafa consumada" (Barba y Montes 2007: 13). Pocas veces como ahora se ha hablado tanto de pornografía en la superficie de la esfera social y pocas veces como ahora ha estado tan presente en los imaginarios y los distintos espacios discursivos ligados a la misma. Puede pensarse, por ejemplo, en la producción narrativa de ficción no catalogada como tal, donde se ha producido una eclosión a este respecto y, donde, además, pueden encontrarse testimonios que servirían al mismo tiempo como espacios de reflexión más próximos a géneros como la crónica o el ensayo, ya sea desde una perspectiva de cuestionamiento del propio género o bajo criterios ligados a la herencia de los Cultural Studies. Es decir, mostrando alternativas a los modelos heteronormativos a través de aspectos que también tienen que ver con la antropología cultural y las subculturas sexuales, el feminismo, la prostitución, la pedofilia, el fetichismo o el sadomasoquismo; mostrando otros códigos de conducta, ajenos a la tendencia estereotipificante, así como diferentes "maneras de entender la praxis sexual, la cotidianidad sexopolítica y los códigos de visualización" (Fernández Gonzalo 2014: 18).

\footnotetext{
${ }^{1}$ Las observaciones de Gracia proceden, en realidad, de su libro, escrito en colaboración con Domingo Ródenas de Moya, Pensar por ensayos en el siglo xx. Historia y repertorio (2015).
} 
Bajo esta perspectiva, podría pensarse que hablar de pornografía se ha vuelto una práctica mainstream, o que conforma, a lo sumo, un gesto progresista, de normalización; pero lo cierto es que sigue encerrando un componente activista y reivindicativo, que ensalza la paradoja de que al porno le siga correspondiendo el lugar de lo obsceno, incluso con la mediación de Internet como lugar de acceso, difusión y producción de contenidos. En palabras de Andrés Barba y Javier Montes, "el porno se mantiene en un lugar absolutamente particular respecto al resto de producciones culturales: accesible de forma general y a la vez oculto de forma general. Al alcance de la mano y sin embargo a una distancia simbólica variable de la esfera pública" (2007: 83).

Quizá sea esta la clave que explique que la aproximación teórica, filosófica y crítica a la pornografía siga siendo, por el momento, una práctica minoritaria, aunque reseñable, cuya dificultad no parece residir tanto en encontrar el tono, como la perspectiva. Dicho de otro modo, el hecho de situarse respecto a lo pornográfico con el fin de reflexionar sobre lo que esa representación dice, tanto de uno mismo como del contexto en el que se producen y perciben esos contenidos, puede llevar a adoptar posiciones incómodas e incluso carentes de credibilidad en los discursos que surgen con tal finalidad. En este sentido, para hablar de pornografía no basta con superar la dualidad pro/contra lo pornográfico, sino que es necesario entender que como sujeto uno siempre se verá afectado por algún tipo de pornografía, y que eso es algo que dificulta toda pretensión de neutralidad en torno a este tipo de temas:

\begin{abstract}
Hay una convención muy extendida cuando se habla de porno. Se acepta, sí, que es un asunto enormemente interesante desde puntos de vista filosóficos, antropológicos, sociológicos o cualesquiera otros. Y a la vez parece darse por hecho que (por interesante que pueda resultar), es algo que solo atañe a los demás. Que siempre son otros [...] quienes conciben, producen, ofertan y consumen porno. [...] Y esa es precisamente otra de las dificultades de hablar sobre porno -o de consumirlo-: la de reconocerse sujeto susceptible a lo porno. (Barba y Montes 2007: 19)
\end{abstract}

Posiblemente, la mejor anécdota sobre este punto sea la protagonizada por Manuel Vázquez Montalbán después de ver la célebre Garganta profunda (1972) en Nueva York. Tal y como lo relata Román Gubern en La imagen pornográfica y otras perversiones ópticas, "después de verla le pregunté su opinión, que fue muy escueta: 'Es inverosímil'" (2005: 26).

La otra dificultad a la hora de hablar de pornografía es, justamente, la de delimitar qué es lo pornográfico, pues no parece posible reducirlo únicamente a la naturaleza de unas imágenes de contenido sexual. Antes al contrario, el porno se mide por "su capacidad funcional para estimular la sexualidad" (Gubern 2005: 9), aunque esto también depende de un punto de vista y, más en concreto, de una determinada metodología: una manera de, puesta en relación con un contexto histórico, político y cultural concreto. 


\section{El estado de LA CUestión}

Uno de los primeros ensayos sobre pornografía, publicado en ámbito nacional, es La imagen pornográfica y otras perversiones ópticas (1989) de Román Gubern. Un ensayo que en su momento tuvo un éxito abrumador y que, tras años agotado, volvió a editarse en 2005 en versión ampliada. Cada capítulo contenía un post-scriptum en el que el autor actualizaba y comentaba las ideas vertidas en el texto original; siendo especialmente llamativo el cambio que había tenido lugar, tan solo unos años después, en cuanto al estatus de la imagen y el discurso pornográfico.

Además de establecer una genealogía de la pornografía como objeto de consumo, en esta obra se explicaba la evolución del mercado y del propio proceso de producción y postproducción del cine para adultos. De esta forma, Gubern no solo contextualizaba una visión muy concreta del porno (que en un primer momento era exclusivamente masculina), sino que repasaba cómo de "la progresiva permisividad de las representaciones eróticas públicas en la pantalla" se pasó de un cine soft-core a lo que hoy se denomina porno duro o hard-core (2005: 10-11). Esto daría lugar, como muestra el listado de películas que va desgranando en su argumentación, a un prolijo repertorio de representaciones de prácticas y juegos sexuales, que cumplía con el principio de la escalada de estímulos y, al mismo tiempo, con el gusto sexual mayoritario del momento.

Así, la sodomización, poco frecuente en los primeros años de despenalización del cine porno (aunque ya presente en Garganta profunda), se difundió en la segunda mitad de los años setenta, según el principio de la escalada de estímulos. Entre las ofertas icónicas de la sodomización figuró de modo importante el dolor/placer de la penetración anal, que el género muestra usualmente a través del rostro de la actriz. Consecuentemente con esta escalada, apareció la práctica de la triple obturación simultánea del cuerpo femenino (vagina, boca y ano). Pero otras variantes del placer erótico (sadomasoquismo, zoofilia, coprofagia) se mantuvieron en los guetos especializados y selectivos de los peepshows y sex-shops, en cabinas de visión individual. (Gubern 2005: 14)

Por otro lado, Gubern otorga a la pornografía un carácter altamente funcional (la gratificación pornográfica en forma de excitación y orgasmo), señalando al mismo tiempo la capacidad didáctica de este tipo de contenidos. A ello vincula la extensión y aceptación de ciertas prácticas sexuales en las culturas occidentales, así como la superación de ciertos tabúes sociosexuales, como podría ocurrir con la exploración de la sexualidad de personas físicamente desfavorecidas. No obstante, si hay algo que de verdad aporta un valor especial a este libro son sus comentarios a la semiótica de la imagen pornográfica, que además se pone en relación, en este contexto, con la imagen cruel a través del cine gore y las snuff-movies.

Se produce, en este punto, un testimonio que puede ponerse en relación $(y$, a veces, en contraste) con voces más actuales que también se han preguntado 
por cómo la pornografía re-produce una subjetividad heteronormativa y patriarcal, y las consecuencias que eso tiene en el imaginario social:

La figura que delata con más nitidez la perspectiva masculinista del género es la práctica no infrecuente de eyacular sobre el rostro de las actrices, en un acto que tiene como resultado iconográfico una suerte de singular condensación freudiana (cara/semen). El semen sobre el rostro femenino [...] implica un mancillamiento simbólico del sujeto poseído por medio de una marca visible de posesión y de dominio. Viene a constituir una marca del macho sobre la parte más expresiva y emocional del cuerpo de la hembra dominada y poseída por él. (Gubern 2005: 21)

De esta forma, en el primer capítulo de la obra, el autor ahonda en cuestiones de retórica de la imagen, a través de todo un imaginario fílmico con el que mostrar esos argumentos. Así, este libro pasa a convertirse en una obra de referencia sobre el estado de la cuestión de lo pornográfico a finales del siglo pasado, cuando el salto a Internet se desconocía y ya empezaban a verse las consecuencias comerciales del consumo doméstico del porno en formato VHS y DVD.

El autor se detiene a explicar detalles sobre el carácter analítico del encuadre y la selectividad analítica del montaje, la utilización de dos cámaras como práctica habitual del cine pornográfico, el uso de insertos parar sustituir eventuales fallos y carencias de los actores, o la importancia de los primeros planos genitales. Un catálogo de especificidades propias del género que Gubern pone en contraste con las formas tradicionales de cine, para después reconocer que también algunos "estilemas y estructuras narrativas de los géneros clásicos [...] fueron absorbidos, recuperados y reciclados por el porno duro desde los orígenes de su despenalización" (2005: 38). Según sus propias palabras, esto produjo una consecuente modificación del estatuto del cine pornográfico, que comenzó a filtrarse en el cine autoral y de ficción convencional, tal y como lo muestran las obras El imperio de los sentidos (1976) de Nagisa Oshima, Los frutos de la pasión (1981) de Shuji Terayama o la más reciente Nine songs (2004) de Michael Winterbottom. Un desplazamiento de los contenidos a través de géneros ajenos a lo pornográfico que se introduce, como se menciona en este ensayo, en géneros como el hentai japonés o los videojuegos.

Teniendo esto en cuenta, se tiene la impresión de que este ensayo, ya revisado y ampliado, aborda todos los lugares de actualidad relacionados con la experiencia pornográfica, pero no es del todo así. Hay un aspecto que resulta insuficiente desde una óptica actualizada y es el de la pornografía como institución económica y de poder, reproductora de códigos de conducta y modelos de subjetividad. Una dimensión del discurso pornográfico que adquiere una gran relevancia en los debates actuales sobre pornografía e identidad, teniendo en cuenta el carácter conservador y la mirada esencialmente masculina de este género.

A este respecto, el propio Román Gubern afirma que hay una total asimetría en el tratamiento de la cuestión de género en el cine pornográfico. Pero no 
solo porque no hayan sido muchas las películas pensadas y realizadas por mujeres para mujeres, sino porque los actores ni siquiera se ven afectados del mismo modo por la obsolescencia consumista. Si hay algo que queda claro en este punto es que el compromiso que el porno establece con el espectador tiene un mayor alcance que el de la simple ceremonia y realización del deseo (masculino), pues su introducción psicológica en el espacio de lo representado opera no solo de forma erótica, sino también ideológica.

De hecho, este sería el testigo que recoge el ensayo La ceremonia del porno (2007) de Andrés Barba y Javier Montes. Una obra también de corte academicista, aunque con un tono más relajado, que vino a ampliar y repensar algunas de las cuestiones apuntadas por Román Gubern en su trabajo y, en concreto, en el Post-escriptum del capítulo primero de su ensayo. La perspectiva, no obstante, resulta del todo diferente en el caso de Barba y Montes, que se aproximan al porno entendiéndolo como un dispositivo comercial y cultural, en un sentido amplio e integrador de ambos términos. Así lo afirman en el capítulo introductorio: "No se trata aquí de analizar los códigos visuales de la imagen pornográfica, ni de deconstruir sus textos, ni de repasar su Historia, ni de estudiar su incidencia social" (2007: 17), sino de explicar la pornografía como una experiencia ubicada en el marco de una ceremonia, cuyas características tratan de dilucidarse a lo largo de la obra.

De esta forma, la cuestión de este ensayo no es tanto la definición o delimitación de lo pornográfico, como el establecimiento de una tesis: la de la pornografía como acontecimiento y ceremonia. Para entenderlo, es fundamental rescatar esa idea de compromiso ya apuntada por Gubern en su ensayo, pero utilizándola bajo una óptica diferente. Si lo porno no es un hecho en sí, su naturaleza vendrá definida por la actitud del consumidor ante su recepción. La excitación, entonces, depende de la relación de un contenido con su contexto y, sobre todo, de la experiencia individual de ese contenido: "En tanto que mi excitación ante el acontecimiento pornográfico no se produzca, ese acontecimiento no es pornográfico, sino cómico, ridículo, inmoral, desagradable o inocuo" (Barba y Montes 2007: 44). En este sentido, para que se produzca la excitación (destino) ha de haberse establecido previamente un compromiso con lo mirado (origen), pues solo así se da comienzo a esa ceremonia del porno que es, por otro lado, la garantía de pervivencia del género.

Establecida esta tesis, los autores del ensayo recorren diversas corrientes teóricas con el fin de establecer un estado de la cuestión integrador y plural, que dé cuenta de la complejidad que encierra un género como este, a pesar de ser concebido y consumido "en formatos rudimentarios reducidos a la mínima expresión narrativa y formal" (2007: 17). Tal y como ellos mismos señalan, ver porno es fácil, pero reflexionar sobre el porno ya no lo es tanto. Así lo muestra el capítulo introductorio, donde se hace un repaso sobre los distintos intentos de delimitación de lo pornográfico, hasta el punto de llegar a vincularlo con el espacio del arte (y negarlo): "En este punto la intuición popular es la correcta: 
arte y porno son cosas absolutamente opuestas, y aun excluyentes. Cuando una cobra sustancia, se desvanece la otra" (2007: 31). ${ }^{2}$

Por otro lado, además de un recorrido por los hitos icónicos de la pornografía internacional (ahora sí, muy a la manera de Gubern, pese a que en ocasiones opere una óptica analítica diferente), cabría destacar los tres aspectos fundamentales de este ensayo. El primero, la crítica a una visión de la pornografía atendiendo a los códigos de la narrativa tradicional (veracidad, coherencia, realismo), pero no para ratificar esa visión inverosímil o carente de sentido, por lo general asignada al cine pornográfico, sino para demostrar cómo su estructura narrativa viene a salvaguardar las condiciones para que se produzca la ceremonia antes apuntada: "La coherencia de la narrativa porno es extraordinariamente lábil y compleja. Está dirigida precisamente a lograr que el espectador se excite" (Barba y Montes 2007: 103). El segundo, el análisis del papel del humor como elemento de control entre las dos esferas puestas en juego en el territorio de la pornografía: la pública (pues la risa responde a los mecanismos de la comunidad) y la privada (a la que pertenecen la excitación y el placer), en "un momento en que se pensó que el porno también podía ser un acontecimiento colectivo" (112), por mucho que el carácter del primero terminara por desarticular el del segundo (y viceversa). El tercero, y posiblemente el más interesante, es el que ahonda en la relación entre el cuerpo pornográfico y el concepto de máscara. Aunque algunos de los juicios relacionados con esto pueden resultar controvertidos al contrastarlos con algunas corrientes feministas ("la máscara no ha reducido a cosa a la mujer [...], sino a estado, que es bien distinto"), resulta interesante esa visión de los actores como personificaciones de emociones en un género que por lo general elude toda clase de afectividad. Según esto, "la actriz que está siendo penetrada en una película porno es una máscara bajo la cual no hay nada sino la personificación de un estado. 'La actriz porno', dice Baudry en La Pornographie et ses images, 'no goza: es el gozo'" (Barba y Montes 2007: 102). Este aspecto, según los autores, mueve a (y refuerza) la excitación; de hecho, esto es algo que también anotaba Román Gubern de forma tangencial en su texto, al apuntar esa necesidad de ver cada vez más que obligaba a encontrar nuevas formas de encuadre (por ejemplo, la frontalidad del cuerpo pornográfico, por lo general, femenino), buscando "el efecto de complicidad con el espectador, para introducirlo psicológicamente en el espacio virtual de su escena" (2005: 57). La máscara funciona entonces como el vehículo y el obstáculo, pues como estado este no puede resultar desmedido ni parecer (que no serlo) fingido: el porno se revela como un acto de fe.

Ahora bien, si lo que se busca es un análisis de lo pornográfico realizado de manera más profunda e incluso conceptual, resulta fundamental acudir al

\footnotetext{
${ }^{2}$ La clave de esta idea aparece perfectamente explicada por el filósofo y escritor Jorge Fernández Gonzalo en su ensayo Pornograffiti. Cuerpo y disidencia, cuando apunta lo siguiente: "Arte y pornografía pueden habitar el mismo soporte, construirse en el mismo objeto, pero es exclusivamente la mirada aquello que discrimina entre ambos: lo artístico pertenecerá al archivo [...], mientras que su índice de excitabilidad pertenecerá a la percepción de cada observador, formará parte de esa suplementariedad obscena que introducen nuestros cuerpos y nuestra mirada sobre el objeto observado" (2014: 17).
} 
ensayo Pornograffiti. Cuerpo y disidencia (2014) de Jorge Fernández Gonzalo. Un ensayo de corte filosófico que aborda este tema desde distintas perspectivas, y donde se dota de un espacio central a cuestiones relacionadas con las políticas de género y la construcción de las identidades sexuales; seguramente, el campo en el que más innovaciones ha habido a este respecto en los últimos años.

También esta obra se adentra en la dificultad de dilucidar una definición satisfactoria de la pornografía, pero partiendo en este caso de dos ideas fundamentales: una, que la pornografía es un invento reciente y, por tanto, indisociable de conceptos como los de "visibilidad, sexualidad, censura y goce" (Fernández Gonzalo 2014: 21). Dos, que "todo es pornografiable", pese a no poder decir que todo sea pornográfico (2014: 18). Según Jorge Fernández Gonzalo, "la pornografía [es] una manera concreta de entender la corporalidad y sus representaciones, erigida sobre unas coordenadas temporales y discursivas específicas y apoyada en novedosas técnicas de reproducción visual" (2014: 19). Se entiende, entonces, que para hablar de pornografía en toda su complejidad ya no pueden eludirse cuestiones como las de identidad (no solamente sexual), privacidad (en constante reformulación con las tecnologías del yo), los avances en tecnología (donde cada vez más el espectador deviene en co-autor) o las distintas modalidades afectivas contemporáneas, que muestran (y tratan de vencer) las jerarquías de poder basadas en una visión del género y el sexo como instituciones económicas.

De hecho, "no pocos autores han señalado la importancia de la pornografía como herramienta de regulación de género y forma de hegemonía de la mirada masculina, occidental, burguesa y heterocentrada" (Fernández Gonzalo 2014: 25); lo que viene a mostrar la importante tarea que queda por hacer a este respecto en un medio totalmente desigual en cuanto a la demanda de diversidad en los contenidos y su oferta. ¿Qué ocurre, si no, con las corporalidades abyectas y periféricas, con las prácticas sexuales no convencionales? En este punto, es fundamental atender a los discursos feministas y sus distintas estrategias a la hora de pensar la identidad y la sexualidad como un construcción sociohistórica y cultural que, por lo mismo, no responde a un modelo cerrado, sino de la multiplicidad. De hecho, como apunta el autor, en los últimos años se ha producido un "cambio completo en la concepción de los cuerpos y las identidades", que "pertenecen a una mirada, a una historicidad, a unas tecnologías de apropiación y representación" (38 y 144) que hacen imposible obviar estas cuestiones.

Muy en sintonía con la visión del género aportada por Judith Butler en tanto construcción, se llega aquí a la conclusión de que también la sexualidad constituye un territorio inestable, ajeno a esa dicotomía sexual tradicional polarizada en el binomio hombre-mujer. A este respecto, en el libro se refuerza una idea moderna que viene a aglutinar el origen de todos los movimientos asociados a la cuestión de género y los códigos sexuales, emocionales, afectivos e identitarios, en auge en las últimas décadas: "La pornografía no es representativa [...] la pornografía es performativa" (Fernández Gonzalo 2014: 156). Un valor que apunta directamente a la funcionalidad sociocultural del porno, al actuar como garante de las diferencias de género y de un sistema heteropatriarcal, hetero- 
normativo y estereotipificante. En otras palabras, su papel no es el de mostrar una realidad, sino el de construirla y rentabilizarla, incluso en el caso de los formatos más abiertos a filtrar códigos sexuales tradicionalmente rechazados o patologizados, en función de un momento u otro de la historia. Ese sería el caso del cine amateur, que no siempre funciona como ventana a otras prácticas y sexualidades posibles, siendo como es un género que tiende hacia la conservación de una visión heteronormativa, incluso en torno a las prácticas que contestan ese esquematismo.

En este punto, el autor menciona cómo suelen ser absorbidas las prácticas de este tipo, citando el caso de la pornografía lésbica, que suele incorporarse a producciones dirigidas a un público masculino y no tanto para consumidoras lesbianas de porno. Algo parecido comentaba ya Román Gubern en su ensayo, al hablar de cómo ciertas prácticas vinculadas al triolismo seguían una pauta sexista similar: mientras en las relaciones de un hombre con dos mujeres se insertan siempre juegos sexuales entre ellas, en las relaciones de una mujer con dos hombres ocurre justo lo contrario. Una hipocresía icónica que viene siendo el campo de batalla de la teoría queer y los movimientos feministas, que asumen de raíz la violencia de las formas de categorización tradicionales y las formas en que estas se perpetúan a través de la pornografía y otras estructuras de poder.

Como inciso, para una aproximación a estas cuestiones de género y representación es recomendable la lectura de un pequeño ensayo elaborado por Marisol Salanova bajo el título Postpornografía (2012), reeditado tres años más tarde como anexo en Enterrados. El ocaso de los cuerpos (2015). En él, Salanova reflexiona sobre el carácter instrumental del elemento pornográfico en el arte contemporáneo, también bajo la perspectiva del porno como instancia de subjetivación. Para ello, la autora se adentra en los discursos que han problematizado el modelo polarizado y heterosexual a la hora de representar los cánones corporales y de sexualidad en el terreno de la pornografía y el arte, pero elevando la cuestión hacia la representación de las identidades sexuales en un contexto en el que el sexo se utiliza como elemento diferenciador. De este modo, Marisol Salanova realiza una síntesis crítica de los presupuestos más representativos de movimientos como el feminismo, incluyendo el feminismo prosexo, el transfeminismo, el movimiento postporno, los Porn Studies o la teoría queer; reconociendo, además, el valor que han tenido y tienen estas iniciativas en cuanto a la liberación de prejuicios en torno a la sexualidad, el género y la corporalidad en el debate actual sobre estas cuestiones.

\section{LA ALTERIDAD CULTURAL}

Como se señala habitualmente, la gran revolución en el porno se vivió con la llegada de Internet y el acceso a contenidos pornográficos por vía digital. La pornografía, siempre a la vanguardia de la modernidad tecnológica, acometió un cambio en su propia naturaleza que mostró de manera más contundente hasta qué punto la intimidad, cuyos códigos se vieron también reformulados en este medio, era y es uno de sus elementos fundamentales. Se alcanzaba, así, un 
nuevo estadio en cuanto al consumo de pornografía, instalando la intimidad del espectador en el corazón mismo del porno (Barba y Montes 2007).

Esto suponía, por un lado, que el espectador pasaba a convertirse no solo en poseedor del acontecimiento pornográfico, sino en coautor de lo que allí se mostraba, e incluso en productor de contenidos. Dicho de otra forma, Internet no solo supuso el medio de acceso a un tipo concreto de representación, sino una extensión de lo pornográfico que convertía cualquier dispositivo con conexión en una webcam siempre encendida $y$, en consecuencia, a cualquier sujeto con un cuerpo en un agente activo de la industria. En palabras de Marisol Salanova, en la actualidad, "cualquier persona con conexión a Internet y un ordenador con cámara tiene a su alcance entrar a formar parte de la industria del sexo" (2015: 190). De hecho, esto es algo que lleva a repensar el porno amateur, junto con el grueso de la industria que constituyen las páginas de encuentros, videoconferencias anónimas y emisión de sexo en directo, como una posibilidad para la "proyección de las visiones culturalmente distintas en torno al cuerpo y la identidad" (208); a lo que podrían añadirse, también, las sexualidades no normativas y las prácticas eróticas disidentes.

En Fenomenología de la alienación (The Act of Killing) (2014), José Luis Molinuevo establece una teoría de la imagen impura en relación a la violencia, que por momentos podría trasladarse a la reflexión sobre la imagen pornográfica. En este sentido, la clave no la sitúa en el lado de los contenidos, como ya dijimos que tampoco puede hacerse en el territorio de la pornografía, sino en la metodología. Con Internet y el género amateur, por ejemplo, el porno se desliga de su carácter tradicionalmente fake para adentrarse directamente en el de lo real, pese a que no deja de tratarse de un montaje (pues el porno no constituye una experiencia de facto, sino su representación). Esto vuelve a llevarnos a esa idea del porno como ceremonia que conecta a su vez con una de las tesis centrales del pensamiento de José Luis Molinuevo en este libro: la de la metonimia icónica, según la cual, "el acto de filmar es el acto de matar" (2014: 22), digamos, ahora, de follar. Tal y como comentaba Gubern a propósito de esto mismo, "Ios actores hacen el amor, en efecto, para la cámara, es decir, para la mirada ulterior del espectador, bajo el imperativo de la visibilidad óptima" (2005: 19).

Emerge en esta idea el problema sobre los límites de la representación que son, curiosamente, los que activan el deseo y los mecanismos del placer. La necesidad de apropiación, continuamente aplazada en pornografía, se compensa a través de una visión de los cuerpos que solo el espectador puede alcanzar desde esa perspectiva, privilegiada, de factibilidad de la carne (por otro lado, negada a los actores). Se logra, así, una complicidad con el espectador que busca su implicación, el pacto para que se produzca el acontecimiento pornográfico, que llega a su máxima expresión en el contexto digital, el verdadero lugar de los contenidos personalizados y donde, a través de la privacidad y del anonimato que permiten estos espacios, el espectador puede llevar al extremo la práctica DIY, convirtiéndose en productor y actor de contenidos. De esta forma, también la pornografía, como género del exceso del cuerpo (Molinuevo 2014) se vuelve una fuente de autodescubrimiento $y$, por tanto, un género innovador en el te- 
rritorio de la subjetivación, al dinamitar el vínculo tradicional entre subjetividad y deseo, resultado de una concepción dicotómica de la fisiología humana (Fernández Gonzalo 2014).

Por su parte, la perspectiva que emerge a este respecto aporta un nuevo giro a los planteamientos en torno al porno: el sexo es (y así debe tratarse) una categoría política, por lo que una reflexión crítica y conceptual sobre la pornografía adquiere también ese carácter. Como puede adivinarse, esto enfrenta de nuevo el problema en torno a los límites de la representación, al desplazar el foco de interés no tanto hacia el hecho de hacer visible lo (ya) visible sino, por el contrario, a hacer visible lo que habitualmente se oculta a la mirada, porque no debe ser mostrado de acuerdo con ciertas normas y convenciones sociales que no son sino dispositivos opresores de poder.

El porno, desde siempre, se ha movido en el mercado tratando de satisfacer el gusto de la mayoría, aun cuando su estrategia comercial se ha basado en adaptar, o bien recodificar, nuevas posibilidades de consumo tanto a nivel funcional como de identidad y placer sexual. Por oposición a esto, es decir, al canon de lo pornográfico, puede pensarse en la noción de lo abyecto, como aquello no catalogable, de extensiones movedizas y perfiles vulnerables (Fernández Gonzalo 2014) que viene a mostrar lo escurridiza que es la noción de identidad, sobre todo en materia de comportamiento sexual.

No hemos de pagar un precio por reconocernos en nosotros mismos, en nuestras inclinaciones y voliciones. El objetivo pasa por encontrar, como propone Mario Mieli (1979), un Eros polimorfo y múltiple que no represente un encadenamiento a formas encorsetadas de ingeniería identitaria, sino un terreno de liberación y elección. Este Eros líquido no consiste en la oposición abierta y estéril a la norma, sino en un refuerzo a la disidencia intersticial, [...] a los espacios periféricos. (Fernández Gonzalo 2014: 188-189)

Esta idea, que por otro lado es base de la teoría queer, articula más que una posibilidad de identidad: la ruptura de ese concepto cuando responde no a una visión discontinua y versátil del mismo, sino a efectos normalizadores de las identidades sexuales:

Las identidades queer pueden así asumir estratégicamente roles y posicionamientos preestablecidos o confrontar signos de construcción identitaria ya dados, si bien lo más interesante, por decirlo de algún modo, es la posibilidad de mostrar la fluidez de las identidades, su condición mutable y prostética, así como su dependencia de estrategias políticas o lúdicas (o ambas). Este nomadismo, señala Javier Sáez, es justamente lo que pone de relieve la futilidad de asentarse sobre una identidad definitiva, de componer una versión última del cuerpo, el género o la sexualidad (Sáez 2004). La propuesta queer se alza contra el catálogo fijo de la tipología sexual, incluso en sus variaciones más novedosas como gays, lesbianas, travestis o drag queens. (Fernández Gonzalo 2014: 190)

Puede entenderse, entonces, la relevancia de los discursos que asumen y participan de esta creciente politización de las representaciones de la sexuali- 
dad, aun cuando el sexo se revela como un asunto esencialmente privado (Barba y Montes 2007: 87). De acuerdo con esto, es fundamental atender al trabajo de un autor como Paul B. Preciado, cuya obra aporta no solo una mirada crítica sobre las construcciones de subjetividad y la cuestión de género, sino la asunción de un discurso pornográfico que culmina, finalmente, con el uso del propio cuerpo como texto $y$, por tanto, como elemento de control sobre la propia sexualidad. Ese "habitar la masculinidad" al que se refiere en algunas entrevistas a propósito de su decisión de reprogramar su propio género, muestra un nivel superior de encarnación de esa mirada crítica a las tecnologías de apropiación y representación de los cuerpos y las identidades que desarrolla en sus libros. Bajo una visión de la biología sujeta a su propia historicidad, Preciado dinamita todos los presupuestos tradicionales en torno a la diferenciación sexual, al afirmar que los órganos sexuales como tal no existen, por lo que tampoco resultaría ya operativa una diferenciación entre lo natural (original) y lo derivado. Muy probablemente, la idea que dinamita todas estas cuestiones se concentra en el siguiente enunciado: "El dildo precede al pene" (Preciado 2002: 66), que resulta crucial para entender la raíz de su sistema de pensamiento. Una visión diferente de la filosofía, la sociología, los estudios de género y la sexualidad, que convierten a este autor en una referencia a la hora de atender al discurso pornográfico desde una perspectiva performativa del mismo.

De hecho, ya en Manifiesto contra-sexual (2002) se adelantaba el que sería el núcleo duro de su pensamiento, más tarde desarrollado en el ensayo Testo yonqui (2010), que venía a perfilar una de las propuestas filosóficas más radicales e interesantes (en su concepción estética) de los últimos años. Valgan como ilustración de esta idea las palabras que Marie-Hélène Bourcier dedica a la obra de Preciado en su prólogo a la misma:

Este Manifiesto pone el acento precisamente sobre aquellas zonas olvidadas por los análisis feministas y queer: el cuerpo como espacio de construcción bio-política, como lugar de opresión, pero también como centro de resistencia. En su declinación política, las nuevas tecnologías de la sexualidad que aquí se proponen muestran que el cuerpo es también el espacio político más intenso donde llevar a cabo operaciones de contra-producción del placer.

Se perfila aquí una filosofía del cuerpo en mutación, reclamando formas de hipersexualización y de hiperconstructivismo del cuerpo y de sus órganos sexuales en total ruptura con las soluciones filosóficas y políticas del feminismo tradicional. (Preciado 2002: 12)

En su pensamiento, por naturaleza transversal, no solo se dan cita cuestiones relacionadas con las políticas de representación sexual, las instancias de subjetivación o las identidades minoritarias; se intenta, sobre todo, conocer (y no solo mostrar) lo contradictorio en los imaginarios sociales, para así pasar a proponer una serie de prácticas subversivas de identidad que, frente a la institucionalización de los instintos, termine por liberarlos:

La contra-sexualidad no es la creación de una nueva naturaleza, sino más bien el fin de la Naturaleza como orden que legitima la sujeción de unos cuerpos a 
otros. [...] La contra-sexualidad es también una teoría del cuerpo que se sitúa fuera de las oposiciones hombre/mujer, masculino/femenino, heterosexualidad/homosexualidad. Define la sexualidad como tecnología, y considera que los diferentes elementos del sistema sexo/género denominados "hombre", "mujer", "homosexual", "heterosexual", "transexual", así como sus prácticas e identidades sexuales no son sino máquinas, productos, instrumentos... (Preciado 2002: 19 -20)

De algún modo, podría decirse que el objetivo último de su trabajo es el de desplazar y modificar las posiciones de enunciación de las "tecnologías de la escritura del sexo y del género" (Preciado 2002: 23) para, posteriormente, ejercer una postura de resistencia a la norma, pero bajo una multiplicidad de opciones: "el cuerpo es ya un territorio por el que cruzan órganos múltiples e identidades diversas" (168). La raíz es, por tanto, ontológica. Una revisión analítica de la existencia (sexual), basada en una tesis elevada a certeza: la superación de la dualidad naturaleza-cultura/tecnología, que ya estaba de algún modo formulada en propuestas como las de Judith Butler y su idea del género performativo, o de Simone de Beauvoir y su célebre "no se nace mujer, se deviene". Su propuesta es, por tanto, la de cubrir ciertos espacios problemáticos de los feminismos, asentados en una distinción entre sexos que es, precisamente, la que se ha pretendido abolir.

Mi esfuerzo consiste en un intento de escapar al falso debate esencialismoconstructivismo [...], en confrontar los instrumentos analíticos tanto de la teoría queer como de las filosofías post-estructurales [...] a ciertos órganos y objetos impropios a los que ni el feminismo ni la teoría queer han querido o han podido dar respuesta. (Preciado 2002: 76)

Lo apunta igualmente Eloy Fernández Porta en Eros. La superproducción de los afectos, rescatando el lema de Simone de Beauvoir, pero por oposición: "tampoco se nace hombre". Lo que viene a decirse con esto es que la producción biopolítica del concepto de género, dentro de los límites del mercado, desplaza la importancia de la revisión de esos códigos hacia la explotación y su rendimiento económico. En otras palabras, el objetivo no sería "corregir los errores históricos, sino [...] trasladar a la masculinidad ese mismo carácter cambiante y permanentemente renovado [...] por medio de la masculinización de la moda" (2010: 164). Una nueva instrumentalización de la cuestión de género que no lleva a transformar la visión tradicional de las identidades, sino que busca formas nuevas, dentro del seno de la esfera social, de legitimar los mismos valores, aunque en términos más eficientes. Así lo apunta Eloy Fernández Porta a este respecto: "no vivimos en un mundo 'cada vez más feminizado', sino en un mundo donde la dominación masculina se legitima de manera mucho más convincente y amable que antes, porque ha incorporado un conjunto de modos, términos y estilemas 'femeninos'" (2010: 166).

Al igual que en el caso de Paul B. Preciado, también los textos de Eloy Fernández Porta guardan un modo de aproximación a la pornografía que asume 
una perspectiva transversal e integradora que se asocia a temas tan diversos como el afecto, el mercado, la moda o los reality shows y que, pese a no ser el objeto central de sus análisis, estos se convierten en fundamentales a la hora de entender la naturaleza de lo porno y el grado de interés que ese discurso (y su producto) despierta en la actualidad. Si se piensa en la cuestión de género, por ejemplo, el autor conviene en ejemplificar el modo en que, en no pocas ocasiones, la alta cultura pasa a legitimar el sexismo utilizando mecanismos más sofisticados y escudados en la apariencia de lo políticamente correcto. De esta manera, el do it yourself que estaba en la naturaleza misma del homo sampler, "ya no se refiere solo a abrir un blog o crear un sello discográfico indie, sino también a generar y articular de manera metamediática un espacio relacional que, de otro modo, quedaría por entero en manos del gran sistema de producción" (2010: 132-133).

Una idea que resulta crucial si se desplaza al territorio de la producción de un discurso pornográfico elaborado por y para mujeres, pero también si se introduce en el espacio de la intimidad y el control de la propia sexualidad. Ahí descansa la clave de esa reprogramación de los discursos de poder y la reapropiación del placer sexual que tiene su máxima expresión en Testo yonqui de Paul B. Preciado. Un texto concebido como un ensayo corporal, en un periodo histórico que el autor denomina farmacopornográfico. En él se realiza, además, un análisis detallado del funcionamiento de la industria pornográfica a la luz de sus últimas innovaciones, así como de las consecuencias que esto ha tenido en la modulación del imaginario social, en cuanto fuerza de la economía mundial. Utilizando sus propias palabras: "las verdaderas materias primas del proceso productivo actual son la excitación, la erección, la eyaculación, el placer y el sentimiento de autocomplacencia y de control omnipotente. El verdadero motor del capitalismo actual es el control farmacopornográfico de la subjetividad" (2008a: 36).

Un concepto interesante, el de la farmacopornografía, que llama la atención sobre cómo la farmacología ha logrado modular las subjetividades hasta el punto de haber motivado la transformación de conceptos como los de feminidad, masculinidad, homosexualidad, conciencia o libido, para pasar así a gestionarlos como bienes de intercambio. La idea que subyace, como puede imaginarse, es que la ciencia ya no sirve únicamente para describir la realidad, sino que fundamentalmente la crea. Una visión que, en última instancia, obliga a cambiar la visión tradicional de lo natural, y a desviar el centro de atención no ya hacia la naturaleza del cuerpo, sino hacia los "procesos culturales, políticos, técnicos a través de los cuales el cuerpo como artefacto adquiere estatuto natural" (Preciado 2008b).

Por su parte, esto es algo que conecta con la postura que asume Eloy Fernández Porta otro de sus ensayos, Emociónese así, donde el autor se interroga sobre los procesos de construcción de la subjetividad en la época actual, con el fin de elaborar una sociología de las emociones (en la que el sentimiento se concibe como capital), que culmina, curiosamente, en una teoría de los afectos ampliamente codificada. En este sentido, "las aportaciones que surgen del giro 
emocional desmienten que el sentimiento sea un asunto 'puramente personal e íntimo' y proponen abordarlo como un dato o una secuencia de datos que definen el mundo relacional de manera consciente y necesaria" (Fernández Porta 2012a: 195).

Si se comparan ambos discursos o, mejor todavía, si se ponen en relación, puede verse cómo el objetivo que subyace en las obras de estos dos autores no busca tanto mostrar la complejidad de los asuntos relacionados con la sexualidad, la pornografía, la identidad y los afectos, como su inserción en un contexto sociohistórico y cultural que, en última instancia, viene a mostrar cómo todas estas esferas han pasado a convertirse en fuerza económica y reflejo de ciertas estructuras, tecnologías y jerarquías de poder. Si para Paul B. Preciado sexo y sexualidad ocupan hoy el centro de la actividad política y económica, para Eloy Fernández Porta la subjetividad es producción, condicionamiento y producto.

El punto de engarce entre ambas perspectivas es el del capitalismo emocional, del que la pornografía constituye parte esencial de su constitución y vanguardia.

\section{GIRLS WHO LIKE PORNO}

Como ha podido verse hasta el momento, en los últimos años, la pornografía se ha pensado en muy distintas dimensiones, dando cuenta así de la prosperidad tanto del género como del propio discurso pornográfico a él ligado. Si hay una primera conclusión que puede extraerse de todo ello es que, pese a que la postura del público mayoritario sea por lo general conservadora y de recelo en prácticamente todos los asuntos relacionados con la cultura, los cambios de registro, códigos, hábitos o estéticas, no ocurre así en cuanto al porno. Esto no quiere decir que la prosperidad de este género haya dado por superados los contratiempos jurídicos y administrativos que, tradicionalmente, han operado contra su difusión. Sin embargo, en su naturaleza están la transgresión y la explotación de tabúes sociosexuales, en muchos casos presentados como innovación o giro estético, si se piensa en cómo esto puede llevar a la mostración (y posterior naturalización) de modos distintos de erotismo, relación, subjetivación y sexualización de los cuerpos. Es así, de hecho, como lo abyecto pasa a instalarse en el mainstream sexual. De este modo lo puntualizaban Román Gubern en La imagen pornográfica y otras perversiones ópticas al hablar del carácter didáctico y normalizador del cine para adultos; o Eloy Fernández Porta, quien comparte una visión similar a la de este autor con relación al carácter funcional de la pornografía a la hora de naturalizar comportamientos sexuales e incluirlos en el vasto catálogo pornográfico que es Internet:

La manera en cómo se ha reconfigurado el porno en Internet tiene una parte completamente foucaultiana: las taxonomías. Son las distinciones entre lo normal y lo perverso objetivadas en la creación de subgéneros lo que hace posible la difusión del discurso y el conocimiento sobre la sexualidad, y que sirve para popularizar el fisting u otras prácticas que hasta hace pocos años solo sucedían en el más estricto secreto. (Fernández Porta citado por Vanity Dust 2013) 
Entendemos, entonces, que en Internet opera una nueva manera de definir lo pornográfico, que ya no tiene que ver tanto con las cuestiones de forma como con las cuestiones de poder o, lo que es lo mismo, con quien administra el porno. Una idea crucial que ha sido abordada en los últimos años desde muy distintas perspectivas y posturas y que, por lo mismo, ha adquirido un matiz más combatiente, hasta el punto de convertirse en un aspecto ineludible a la hora de hablar sobre pornografía.

Si uno repasa la historia cinematográfica del cine para adultos, apenas encontrará títulos pensados por y para mujeres, como tampoco encontrará muchas excepciones al discurso hegemónico de la representación sexual. Hace falta alcanzar el cambio de siglo para encontrar popularizados ciertos imaginarios sexuales, hasta entonces tan desplazados e ignorados como la perspectiva y experiencia feminista de la pornografía. De hecho, el tema no está exento de polémica, pues el feminismo no implica la renuncia a la pornografía, aunque cuestione la perspectiva desde la que esta se realiza y los puntos en que se basa la motivación erótica, para su disfrute.

No obstante, el feminismo se ha caracterizado, durante mucho tiempo, por mantener una postura contraria al cine pornográfico, que rara vez ha contemplado, casi hasta la actualidad, la posibilidad de un público femenino. Esto es algo que tiene que ver, como puede imaginarse, con el inconformismo de género, la visión ya comentada de la identidad como constructo y, por último, con "el trato que en el porno se establece entre objeto y sujeto" (Fernández Porta 2012a: 157).

Ante unas coordenadas como estas, parece lógico que el debate en torno a la pornografía haya ido virando en las últimas décadas hacia el modo en que se realiza la producción y el consumo de estos contenidos, y que este debate haya estado protagonizado en su mayoría por mujeres. ${ }^{3}$ De hecho, si resulta fundamental atender a este tipo de discursos es porque no solo permiten entender las posibilidades de mutación y expansión que la pornografía tiene a este respecto, sino conocer de primera mano los testimonios que proceden de la propia industria y que, por tanto, ofrecen una valiosa mirada desde dentro de la misma.

En España, aunque esto sería lo de menos, dada la internacionalización de la industria del cine para adultos, el caso más llamativo, por el éxito de su fórmula, lo conforma la cineasta Erika Lust, al frente de la productora Lust Films, fundada en 2005 y con base en Barcelona. Ella misma se define como una activista feminista prosexo, liderando un movimiento internacional que aboga por pensar críticamente, y bajo una perspectiva de género, las representaciones sexuales que produce la pornografía, entendida en este caso como agente performativo sociosexual. Si se tiene en cuenta que una tercera parte del tráfico que se produce en Internet tiene que ver con contenido pornográfico y sexual, es lógico

\footnotetext{
${ }^{3}$ Una postura que pone en cuestión este tipo de juicios puede encontrarse en el ensayo Pornografía. Obsesión sexual y tecnológica (2012) de Naief Yehya, quien critica una visión ahistórica y sexista de la pornografía, básicamente por basarse en una mirada parcial y descontextualizada de la misma.
} 
pensar, como ella misma ha señalado en diversas ocasiones, en la pornografía como el nuevo manual de educación sexual de este tiempo.

Resulta interesante su conferencia "It's time for porn to change" para TEDxVienna, en 2014, donde, además de explorar estas ideas, realiza un repaso sobre los inicios de su carrera como directora de cine porno, a partir del éxito de su primer corto The Good Girl (2004). Si esto es importante es porque, a partir de ese momento, su nombre se convierte en una marca, en lo que significa Erika Lust en la actualidad: cine porno antimainstream, independiente, con sujetos (sobre todo mujeres) deseantes, en contextos que concilian la progresión narrativa con la estimulación erótica y en los que, por lo general, se ofrece una visión sofisticada y estetizada de las relaciones sexuales (y sin que esto excluya modalidades diversas de corporalidad, erotismo o identidad sexual). El objetivo de su proyecto es, en definitiva, crear cine para adultos desde una perspectiva feminista y, en último término, una pornografía que además de persuadir, seduzca tanto al público como al mercado. En algún momento de su trayectoria, Erika Lust decidió hacer el porno que quería ver para, después, hacer también posible el porno que otros demandaban. Así lo muestra su proyecto $X$ Confessions que, en la actualidad, cuenta con nueve volúmenes de testimonios y fantasías sexuales anónimas que los usuarios pueden ir dejando en su web para su (posible) selección por parte de su productora. Por otro lado, además de la realización de cortos y largos fílmicos, Erika Lust es también autora de varios libros de naturaleza erótica o ensayística, entre los que destaca Porno para mujeres (2008). Un texto en el que se destierra el mito de la pornografía solo para hombres, y en el que la autora realiza una revisión de la historia de la pornografía y del papel de la mujer en esta industria, a través de un discurso renovado sobre la sexualidad, de clara apertura en estos temas.

No obstante, el porno que se realiza bajo la marca de Erika Lust no es únicamente porno para mujeres (su público es también masculino), como tampoco explota una visión naïve de lo pornográfíco. Tal y como ella misma afirmaba en su conferencia para TEDx, "el sexo puede ser sucio, pero los valores han de ser los correctos". Esa sería la clave de su trabajo y, sobre todo, de su forma de repensar la pornografía, en tanto una aproximación crítica a estos temas no supone tanto trasladar el objeto de lo pornográfico hacia otro lado, como cambiar su metodología y el modo de gestionarlo.

Por supuesto, esta es una postura que también ha sido objeto de críticas por parte de algunos feminismos que, en palabras de Marisol Salanova, con frecuencia le han señalado cómo su cine "no escapa a estereotipos sino que explota otros relacionados con la mujer, solo que diferentes a los que plantean la mayoría de películas porno dirigidas a un público masculino" (2015: 219). La crítica, desde luego, parece pertinente, pero también obvia la raíz de un trabajo en el que tan importante es lo que se muestra como el lugar desde el que se muestra; pues ese parece ser hoy el elemento diferenciador en el terreno del hacer pornografía. 
Así lo explicó Erika Lust en una entrevista para SModa de El País:

\begin{abstract}
Yo suelo decir que una manera de buscar buen porno, si vas navegando online, es ver si hay una página about. ¿Hay una persona ahí detrás, hay alguien con nombre, apellido y foto, del que quizás puedas leer una entrevista para conocer sus opiniones o ver el making of de una de sus películas, para sentir que hay realmente alguien que fabrica todo esto con unos valores? Es lo que se llama pornografía ética. Es decir, que se tiene una garantía de que se ha tratado bien a los actores, que conocen el guion y están de acuerdo con las escenas que van a rodar, que nunca se les va a obligar a hacer algo con lo que ellos no están de acuerdo o que se les hacen pruebas y controles de salud y de ETS que ellos comparten. [...] Para mí es importante la mirada femenina. Yo tengo detrás de mí un equipo de mujeres, quince mujeres que rodamos las películas: directora de arte, de fotografía, vestuario, maquillaje, asistente de dirección. [...] Yo muestro mujeres que tienen el poder de su sexualidad, que hacen cosas que ellas quieren hacer. Eso no significa siempre que tienen que ser las dominantes, porque no tiene nada que ver con eso, ya que tú puedes perfectamente tener el poder y ser sumisa. Significa que es importante mostrar el consentimiento, situaciones en las que los integrantes están a gusto y han decidido hacer lo que hacen, por muy fuerte o escandaloso que pueda resultar para algunos. (Erika Lust citada por Abundancia 2017)
\end{abstract}

Por lo mismo, la existencia de cineastas detrás de las cámaras con una perspectiva similar a la de esta autora es, por el momento, un caso minoritario. Quizá por eso, también Erika Lust se ha propuesto financiar y producir a directoras de cine para adultos, en una campaña internacional que no busca, parafraseando a la cineasta, sacar a las mujeres del porno, sino involucrarlas en él, situándolas detrás de las cámaras. Según su propio criterio, es el momento idóneo para que se produzca un cambio en el mundo del porno; pero no un cambio hecho de cualquier manera: es fundamental contar con mujeres en los puestos de poder de la industria pornográfica y es fundamental, también, aprovechar que, gracias a la red, la pornografía está a un clic de cada potencial usuario. Una distancia que una década atrás era impensable y que ha hecho que el debate sobre el porno se haya intensificado socialmente.

Como complemento a estos argumentos, resulta interesante considerar la opinión de actrices que, desde dentro de la industria, reflexionan sobre su labor y su papel como mujeres en un contexto laboral aún muy dirigido a satisfacer un gusto heteropatriarcal de amplia demanda. Uno de los casos más conocidos fue el de la actriz Sasha Grey, cuya "popularidad se vio incrementada por las reflexiones en torno a la sexualidad y el arte contemporáneo que realiza en sus espacios de Internet (Myspace y Twitter), donde frecuentemente cita a Jean-Paul Sartre, Baudrillard, etc." (Salanova 2015: 218). Grey, retirada del cine para adultos, imparte charlas y conferencias sobre sexo y educación, al tiempo que participa, aunque de forma eventual, en películas de cine independiente, en un claro intento de reciclaje. Valgan como ejemplos The Girlfriend Experience (2009) de Steven Soderbergh o de Open Windows (2014) de Nacho Vigalondo. 
Por su parte, la versión española de este fenómeno se encarna en la actriz porno Amarna Miller, quien suele despertar bastante polémica con sus declaraciones, dado el carácter contundente de sus afirmaciones, experiencias e ideas en torno a su trabajo y la industria a la que pertenece. No obstante, si su visión resulta interesante, se debe sobre todo al hecho de haber adoptado una posición pragmática sobre su trabajo, que no parece entrar en conflicto con una visión crítica (y feminista) del mismo: "Mi profesión no tiene que ver con mi ideología. [...] Yo hago como todos, vendo mi fuerza de trabajo como lo hace un obrero cuando levanta una pared de ladrillo" (Amarna Miller citada por Congostrina 2016).

De hecho, gran parte del éxito de su personaje viene de la conjunción de sus apariciones en cine para adultos con las reflexiones de carácter intelectual y político que vierte en sus canales online, además de tener su propia página web, con acceso a un blog en el que escribe sobre feminismo, sexo, cuestiones de género, y temas diversos sobre su propia cotidianidad. Es, probablemente, la actriz porno española más mediática de estos momentos, presente tanto en medios de prensa escrita, como en radio y programas de televisión de máxima audiencia. De manera eventual, ha impartido cursos y charlas en universidades, en los que habla sobre empoderamiento, feminismo, pornografía y trabajo sexual. Es colaboradora de espacios como Primera Línea, Playground Magazine y orgasmatrix.com y en 2015 publicó su primer libro, Manual de psiconáutica en la editorial Lapsus Calami.

Aunque su posición dentro de la industria del porno no es la más representativa por tratarse de alguien con éxito suficiente para elegir proyectos y poder poner condiciones a las productoras, su testimonio es interesante, pues muestra el conflicto de intereses y prejuicios que un trabajo como este provoca especialmente en el caso de las mujeres. Así lo expresaba en una entrevista para El País a propósito de la polémica que tuvo el vídeo promocional del Salón Erótico de Barcelona Apricots, en el que participaba como protagonista del mismo:

Estoy harta de ser la actriz porno que lee a Nietzsche, la que deja Bellas Artes y se dedica al porno, harta del estigma social, no soy una ninfómana, no me acostaría con cualquiera, tengo más de dos y tres dedos de frente y sé que hay mucho que cambiar en la industria como la creación de un convenio o un sindicato. (Amarna Miller citada por Congostrina 2016)

Como puede entenderse, ser actriz porno y feminista no parece algo contradictorio a la luz de ciertos testimonios, como tampoco supone tener que realizar en exclusiva porno ético (dentro del cual, además, se inscribiría el porno denominado feminista). Sin embargo, justo en esa idea radica una de las claves de las habituales polémicas que siguen a las intervenciones públicas de esta actriz, a la que generalmente señalan esa contradicción o le niegan incluso la posibilidad de que una cosa pueda darse teniendo en cuenta la otra. En cualquier caso, lo novedoso de sus proclamas no es tanto el mensaje que encierran como el contexto y el sujeto desde el que vienen enunciadas. 
A este respecto, podría recordarse uno de los presupuestos que dio origen al movimiento feminista prosexo, que la actriz porno Annie Sprinkle formuló como una manera óptima de ampliar las posibilidades del discurso pornográfico en clave feminista, negando su denostación: "La respuesta al porno malo no es la prohibición del porno, sino hacer mejores películas porno" (Salanova 2015: 215). Una idea que es la que está detrás de estos distintos espacios y posturas que muestran una tendencia creciente a romper ciertos estereotipos y prejuicios asociados tanto al porno como a la propia visión tradicional de la sexualidad.

Otro ejemplo muy en la línea de lo anterior lo constituye la naturaleza del trabajo de la periodista y cronista Gabriela Wiener, autora de Sexografías (2008). Una serie de crónicas en torno al mundo del sexo (aunque no se limite a él en exclusiva) en la que ella misma se involucra al más estilo gonzo, dando como resultado una imagen bastante acertada de la condición femenina en la actualidad. Sexografías muestra, en cualquier caso, la complejidad (e incluso la contradicción) de algunos sentimientos una vez descontextualizados, pero ahí radica el componente más interesante de esta obra, al permitir el acceso a lo contradictorio de los imaginarios sociales en temas por lo general revestidos de polémica (sobre todo en el caso de prácticas no reconocidas por la ley, como puede ser el caso de la poligamia). Por otro lado, también su trabajo en prensa escrita aborda cuestiones tanto de género como de identidad sexual, donde por lo general forma parte del fenómeno observado, potenciando de esa forma el alcance semántico y provocador de sus textos. Sus artículos aportan cierta frescura y libertad a la hora de abordar unos temas que no están del todo normalizados en el conjunto de la sociedad, como ocurre, por ejemplo, con una de sus últimas vías de exploración: el poliamor, en el que ha encontrado la ecuación perfecta para una vida en pareja y familiar.

Basta, pues, con estos testimonios para ratificar la idea de que la simple reflexión sobre cuestiones de género, sexo, identidad y pornografía se ha vuelto en estos días una práctica política, pues en su naturaleza está, la mayoría de las veces, abogar por el cambio en la gestión, la orientación y la producción del discurso pornográfico. Lo mismo da, a estos efectos, que estos discursos se generen en las páginas de un ensayo o en el seno de una página web o una red social. Lo que interesa ahora es el alcance de estos discursos, por lo que tan válida es la generación de pensamiento en la red como el discurso que sigue las vías tradicionales (pero que no siempre encuentra un hueco en el sector editorial). No obstante, la gran ventaja de estas nuevas posibilidades está en la apuesta por la difusión abierta de contenidos, porque eso implica la generación y actualización bajo demanda de los mismos y una confrontación "inmediata" y en abierto de los presupuestos presentados. Es, en definitiva, otra forma de gestionar la información que permite superar los circuitos habituales de publicación, devolviendo el discurso sobre pornografía al mismo punto en el que la propia pornografía se origina.

Se prueban, también, otras formas de legitimación que escapan al tradicional peso de los sellos editoriales, lo que sin duda favorece la proyección de nuevos protagonistas dentro del ensayo escrito y producido en España. Ya 
se dijo, además, que con frecuencia la pornografía se mueve en el espacio de lo novedoso, a veces anticipando cuestiones que suelen verse desplazadas del discurso hegemónico en torno a la representación del cuerpo y la sexualidad, aunque no se limite solamente a este tipo de temas. El debate sobre pornografía huye, por lo general, de lo extremo y lo exagerado, porque ya no lo necesita. El objetivo ahora no tiene ya tanto que ver con los límites de lo pornográfico como con las posibilidades que esto ofrece para "la libertad de los cuerpos y de los flujos, de las mentes y de las relaciones" (Fernández Porta 2012b). Así lo manifiestan las autoras citadas hasta el momento y, más en concreto, la visión poliédrica y plural que proyectan del hecho pornográfico y su propia sexualidad.

\section{Algunas CONCLUSiOnes}

Como ha podido verse hasta ahora, además de haberse producido una intensificación en los discursos sociales de temas como el porno o la identidad sexual, el propio tratamiento de estos temas muestra ya de partida una sensibilidad favorable hacia la reflexión, también conceptual, sobre pornografía. Para lograrlo, muchos de estos autores han optado por reformular el estilo sobrio del ensayo tradicional con propuestas que han acabado por llevarlo a terrenos discursivos más sugerentes y atractivos para el lector contemporáneo. Este modelo de escritura, que podría denominarse transversal, no se limita solamente a la pornografía, sino que la aborda desde perspectivas y espacios múltiples, pero a la luz de un mismo criterio o tesis de aproximación. Así, la cuestión de la pornografía emerge en muchos casos en discursos que hablan sobre temas que en principio podrían parecer ajenos a ella, inscribiéndola de este modo en lo que podría denominarse, de manera más amplia, un ejercicio de crítica cultural. Es posible que esto sea lo que más valor ha aportado a estos discursos y lo que explica, también, el éxito y acogida mediática de los mismos.

Son paradigmáticos los casos de los autores Eloy Fernández Porta y Paul B. Preciado, que por un lado asumen de forma crítica la tradición ya establecida y, por otro, proponen su propia genealogía cultural. Lo que se logra con ello es la posibilidad de repensar un ideario lingüístico, semiótico y semántico a la luz de criterios y referentes culturales en ocasiones inéditos y por lo general ajenos al discurso académico y filosófico. No obstante, esta estrategia no ayuda solamente a reforzar el alcance semántico de los textos, sino que busca desestructurar el complejo de prejuicios que en ocasiones asoma en torno a estas cuestiones, pero ahora adoptando un registro más próximo al de sus potenciales lectores. Un buen ejemplo de esto último se encuentra en el ensayo Testo Yonqui de Paul B. Preciado, en el que el autor inyecta un componente literario a un texto que, en esencia, presenta un ensayo.

Se trata, pues, de un giro estético que busca dar solución a la demanda actual en materia de ensayo, con el fin de liberarlo de la tensión tradicional entre forma y contenido, pero sin que la profundidad de pensamiento se vea afectada en absoluto. Un texto paradigmático de esta tendencia sería, por ejemplo, el ensayo Emociónese así de Eloy Fernández Porta, en el que termina de perfilarse 
un estilo también presente en otras de sus obras y que resulta el vehículo perfecto para su sistema de pensamiento. Otro ejemplo de cómo pueden ampliarse los espacios y objetos de reflexión, pero bajo formas renovadas de discurso, lo constituye el ensayo Pornotopía. Arquitectura y sexualidad en "Playboy" en la guerra fría (2010) de Paul B. Preciado, en el que, de nuevo, el autor vuelve a mostrar un programa singular de pensamiento, en forma de propuesta analítica dirigida hacia cuestiones de género, identidad, sexualidad y pornografía. La novedad, aquí, la constituye el enfoque, al tomar la arquitectura como una instancia performativa de identidad y el universo Playboy como "la primera pornotopía de la era de la comunicación de masas" (2010: 15).

La intención que descansa detrás de estos discursos no es sino la de evitar los lugares comunes a la hora de profundizar en los puntos ciegos de las discusiones sobre la experiencia contemporánea, sea por un lado en cuanto a las relaciones afectivas y los códigos emocionales, ahora renovados a la luz de los nuevos medios, o en cuanto a la producción de instancias de subjetivación e identidad con relación a la sexualidad y la pornografía. Esto es, una forma distinta de crítica cultural, además en torno a un tema por lo general alejado de los discursos centrales de pensamiento.

No obstante, y como ya se ha dicho anteriormente, también habría que tener en cuenta aquí las aportaciones que realizan cronistas como Gabriela Wiener o las actrices y otros agentes pertenecientes a la industria pornográfica, pues es ahí donde pueden encontrarse también juicios muy valiosos asociados a todo ello. El formato en estos casos puede ser diferente (una crónica, un blog, un vídeo en Youtube...) pero la orientación y la pretensión no cambia tanto: a saber, descifrar las claves de la pornografía como institución productora de subjetividad y cánones de sexualidad, con el fin de intervenirlos. La pornografía puede ser, como se ha visto, un producto, un fenómeno, una cultura. Esa es la razón por la que sus representaciones obligan a una revisión seria, crítica y argumentada, basada en criterios de complejidad y transversalidad cultural que muestran cómo el proceso de pornificación de la cultura actual no se produce por accidente, sino que encierra un proyecto de ingeniería social que en ciertos términos se presenta ya caduco.

La objeción a algunas de estas posturas puede encontrarse en el ensayo Pornografía. Obsesión sexual y tecnológica de Naief Yehya, en el que el autor lanza una mirada crítica a la posibilidad de pensar una pornografía democrática y sana, cuando en la propia naturaleza del género se encuentran "el secreto, la transgresión y lo inconfesable" (2012: 192). A pesar de no ser tan políticamente correcto, y sin embargo, necesario, en su ensayo se acogen temáticas no tan habituales en la literatura asociada a estas cuestiones, como ocurre con el tema de la explotación sexual, la amenaza de la violación, las snuff movies o la pornografía infantil.

A finales de la primera década del siglo xxı la mayoría de las naciones occidentales han optado por tolerar las producciones que muestran relaciones y comportamientos sexuales de manera explícita, mientras que han preferido sancionar las imágenes que muestran actos sexuales en los que participan 
menores así como ciertas escenas violentas, escatológicas, duchas doradas y romanas (emetofilia o excitación que se produce por el vómito). Por ahora el límite de lo tolerable se establece cuando se combinan imágenes sexuales explícitas con funciones excretorias, con actos no consensuales o con expresiones de violencia. Es muy probable que esta frontera cambie en el futuro y otro tipo de actos o combinaciones parezcan entonces transgresiones inaceptables. (Yehya 2012: 322)

En algunos puntos, su visión de la pornografía es complementaria a la visión aportada por los autores mencionados en este texto; en otros, especialmente en el caso del feminismo y el papel de la mujer en esta industria, su postura resulta más bien crítica con aquellas voces que claman un cambio en las cuestiones de representación y una mayor profesionalización del sector. No niega ciertas necesidades, pero critica la forma de reivindicarlo como una distorsión de lo que singulariza al propio género. De hecho, hay una idea que puede resultar controvertida pero que es, sin embargo, central en su pensamiento. La pornografía, tal y como él la percibe, cumple también una función de domesticación de las pulsiones eróticas, "sin volvernos esclavos de ellas" (Yehya 2012: 323). Dicho de otra forma, si existen fantasías aberrantes, es mejor que sucedan en pantalla a que sucedan en la vida real. Al fin y al cabo, de nada sirve tratar de censurar un contenido: ahí donde existe la demanda, surge siempre su satisfacción.

Si podemos hablar de un mérito del boom pornográfico de la era de la red es que pone en evidencia que el consumidor en su soledad, detrás de la pantalla, no está realmente solo, que sus perversiones por raras e insólitas que sean, no son casi nunca inauditas. Esto debería servir para eliminar sentimientos de enajenación y complejos de culpa. (Yehya 2012: 322-323)

En pornografía terminan siendo tan importantes el sexo como las relaciones de poder que se dan dentro de su sistema, porque el poder es, también, una forma de mover a la excitación y la utilización del cuerpo. Sin embargo, uno de los aspectos más interesantes que ocurre en estos momentos tiene que ver con la cultura digital y la difusión viral de los contenidos pornográficos, pues es así como la pornografía pasa a convertirse en su reverso: "los consumidores se han transformado en productores potenciales y el espectáculo ha invertido el circuito de producción" (Fernández Gonzalo 2014: 58). La leve frontera que separa ahora espacios como los de intimidad y privacidad constituye hoy en día uno de los aspectos más conflictivos en cuanto a la relación de la industria pornográfica con la sexualidad, la privacidad y las identidades digitales.

Sin transgresión no hay pornografía, y al otro lado de la pantalla siempre habrá un espectador polimorfo esperando a que algo suceda con eso. 


\section{OBRAS CITADAS}

Abundancia, Rita (2017): "Erika Lust: 'Me han criticado más por feminista que por hacer porno'", El País. SModa, 21 de abril, accesible en <https://smoda.elpais.com/placeres/erika-lust-me-criticado-mas-feminista-porno/> [última visita: 25.7.2017].

Azúa, Félix (2010): "La filosofía en el vertedero", El País. Babelia, 8 de mayo, accesible en <https://elpais.com/diario/2010/05/08/babelia/1273277546_850215.html> [última visita: 25.7.2017].

Barba, Andrés, y Montes, Javier (2007): La ceremonia del porno. Barcelona, Anagrama.

Congostrina, Alfonso L. (2016): "Amarna Miller: 'Si solo rodara porno feminista no pagaría ni media factura'", El País, 7 de octubre, accesible en <https://elpais.com/ ccaa/2016/10/05/catalunya/1475688811_276538.html> [última visita: 26.7.2017].

Dust, Vanity (2013): <https://www.vanitydust.com/blog/vanity-dust-de-reenganchemeets-eloy> [última visita: 22.7.2017].

Fernández Gonzalo, Jorge (2014): Pornograffiti. Cuerpo y disidencia. Madrid, Libros de Ítaca.

Fernández Porta, Eloy (2010): Eros. La superproducción de los afectos. Barcelona, Anagrama.

- (2012a): Emociónese así. Anatomía de la alegría (con publicidad encubierta). Barcelona, Anagrama.

— (2012b): "Eloy Fernández Porta. Entrevista sobre Postpornografía". En <https://www. youtube.com/watch?v=Uvvgzu1u6yk> [última visita: 25.7.2017].

Geli, Carles (2017): "La gran mutación del ensayo", El País, 12 de junio, accesible en <https:// elpais.com/cultura/2017/06/12/actualidad/1497290102_839562.html> [última visita: 25.7.2017].

Gracia, Jordi, y Ródenas de Moya, Domingo (2015): Pensar por ensayos en el siglo xx. Historia y repertorio (2015). Bellaterra, Edicions UAB.

Gubern, Román (2005): La imagen pornográfica y otras perversiones ópticas. Barcelona, Anagrama.

Lust, Erika (2012): "It's time for porn to change". En <https://www.youtube.com/ watch?v=Z9LaQtfpP_8> [última visita: 23.7.2017].

Molinuevo, José Luis (2014): Fenomenología de la alienación (The Act of Killing). Salamanca, Archipiélagos.

Preciado, Paul B. (2002): Manifiesto contra-sexual. Madrid, Opera Prima.

- (2008a): Testo Yonqui. Madrid, Espasa Calpe.

_ (2008b): "Farmacopornografía", El País, 27 de enero, accesible en <https://elpais.com/ diario/2008/01/27/domingo/1201409559_850215.html> [última visita: 23.7.2017].

_ (2010) Pornotopía. Arquitectura y sexualidad en "Playboy" durante la guerra fría. Barcelona, Anagrama.

Salanova, Marisol (2015): Enterrados. El ocaso de los cuerpos. Murcia, Micromegas.

Yeyha, Naief (2012): Pornografía. Obsesión sexual y tecnológica. México, Tusquets. 